\title{
Trends in maternal mortality at the University of Calabar Teaching Hospital, Nigeria, 1999-2009
}

This article was published in the following Dove Press journal:

International Journal of Women's Health

6 August 2010

Number of times this article has been viewed

\section{TU Agan' \\ El Archibong' \\ JE Ekabua' \\ El Ekanem' \\ $S$ E Abeshi' \\ TA Edentekhe ${ }^{2}$ \\ EE Bassey ${ }^{2}$}

'Department of Obstetrics and Gynecology and ${ }^{2}$ Department of Anesthesia, College of Medical Sciences, University of Calabar Teaching Hospital, Nigeria
Correspondence: TU Agan Department of Obstetrics and Gynecology, University of Calabar Teaching Hospital, Calabar, Nigeria Tel +234803082 2526 Fax +234807477 440I Email evitomtu@yahoo.com
Background: Maternal mortality remains a major public health challenge, not only at the University of Calabar Teaching Hospital, but in the developing world in general.

Objective: The objective of this study was to assess trends in maternal mortality in a tertiary health facility, the maternal mortality ratio, the impact of sociodemographic factors in the deaths, and common medical and social causes of these deaths at the hospital.

Methodology: This was a retrospective review of obstetric service delivery records of all maternal deaths over an 11-year period (01 January 1999 to 31 December 2009). All pregnancyrelated deaths of patients managed at the hospital were included in the study.

Results: A total of 15,264 live births and 231 maternal deaths were recorded during the period under review, giving a maternal mortality ratio of 1513.4 per 100,000 live births. In the last two years, there was a downward trend in maternal deaths of about $69.0 \%$ from the 1999 value. Most (63.3\%) of the deaths were in women aged $20-34$ years, $33.33 \%$ had completed at least primary education, and about $55.41 \%$ were unemployed. Eight had tertiary education. Two-thirds of the women were married. Obstetric hemorrhage was the leading cause of death $(32.23 \%)$, followed by hypertensive disorders of pregnancy. Type III delay accounted for $48.48 \%$ of the deaths, followed by Type I delay (35.5\%). About $69.26 \%$ of these women had no antenatal care. The majority (61.04\%) died within the first 48 hours of admission.

Conclusion: Although there was a downward trend in maternal mortality over the study period, the extent of the reduction is deemed inadequate. The medical and social causes of maternal deaths identified in this study are preventable, especially Type III delay. Efforts must be put in place by government, hospital management, and society to reduce these figures further. Above all, there must be an attitudinal change towards obstetric emergencies by health care providers.

Keywords: trends, maternal mortality, Nigeria

\section{Introduction}

It is well known that the main indicator of a society's level of development is its state of maternal health, which also serves as an indicator of health care delivery system performance. ${ }^{1}$ The ultimate failure of obstetric care is death of the mother, which often includes the baby as well. Reduction of maternal mortality is top on the agenda of many global efforts, such as the Safe Motherhood Initiative. Reduction in maternal deaths by $75 \%$ in 2015 is a cardinal target of the millennium development goals. ${ }^{1-3}$ However, with less than six years to go until 2015, the year for realization of a two-thirds reduction in maternal mortality, Nigeria's maternal mortality figures remain unacceptably high, as in other countries in the developing world, even though the causes are mostly preventable. It is known that most midwives and obstetricians may go through their entire careers without seeing even one maternal death in the developed countries. ${ }^{4}$ It would therefore 
appear that every woman in Nigeria in particular, and in the developing world in general, struggles to survive pregnancy, childbirth, and the puerperium. Compared with countries like Japan, which has a female life expectancy of 86.1 years, Nigeria has a female life expectancy of 47.3 years, and in this regard is ranked 182 nd by the United Nations. ${ }^{5}$ Even some of the sub-Saharan African states have better female life expectancy, including Ghana (60.5 years), Gambia (60.3 years), Togo (60.1 years), Chad (52.0 years), and Cameroon ( 50.8 years), and these figures are obviously better than those in Nigeria. ${ }^{5}$

The death of a woman during pregnancy or in pregnancyrelated circumstances has an emotional impact not only on the attending health care provider but also on the family. As a result, maternal mortality continues to generate serious public health concerns because of its social, economic, and political implications. ${ }^{1}$ It is even more worrisome when such deaths are preventable, ${ }^{6-9}$ particularly when the factors that result in the three known delays are adequately tackled. ${ }^{1-3,6,10,11}$ In 1991, Deborah Maine stated that delays in the management of pregnancy complications are the key determinants of maternal mortality in the developing countries. ${ }^{12}$ Type I delay results from failure to seek medical treatment on time (40\%); Type II delay results from difficulty in transportation (20\%); and Type III delay occurs when the woman has arrived at the hospital (40\%). ${ }^{1,13,14}$ The third type of delay, that occurs within the health care facility, appears to be common throughout Nigeria in particular and in the developing countries in general. ${ }^{1}$ The situation at the University of Calabar Teaching Hospital is no exception. We present recent trends in maternal mortality at this tertiary hospital, situated in the Niger Delta region of Nigeria, and providing tertiary health care to over 3.5 million people of the Cross River State of Nigeria and, until recently, Akwa Ibom State and the neighboring Republic of Cameroon and Equatorial Guinea.

The Cross River State of Nigeria covers a large area with a very difficult geographic terrain. It has a population of about 3,155,932 people, with a population growth rate of $2.99 \%$, and $45.5 \%$ of the population are rural dwellers. ${ }^{15}$ About $22 \%$ of the total population is in the reproductive age group (15-49 years).

\section{Materials and methods}

This was a descriptive study of maternal deaths at the University of Calabar Teaching Hospital, which is the only tertiary health institution in the Cross River State (Niger Delta region) of Nigeria. Approval for this research was given by the Research and Ethics Committee of the hospital.
All the medical records of women who died in the obstetrics department between January 1999 and December 2009 were retrieved from the hospital medical records and reviewed for immediate and remote causes of death. A total of 231 maternal deaths were identified and subjected to in-depth analysis.

Factors analyzed included the sociodemographic characteristics of the women who died, the main causes of death, pattern of health-seeking behavior for antenatal care/ delivery, and place of labor and delivery. Also assessed were the types of delays leading to maternal death, causes of maternal death in hospital, as well as duration of hospital stay before death.

\section{Results}

During the study period, a total of 15,264 live births were recorded in the hospital. A total of 231 maternal deaths were recorded, giving a maternal mortality ratio of 1513.4 per 100,000 live births. No post mortem was conducted after any of these maternal deaths because of objections from relatives. The annual trend in maternal mortality in the hospital is shown in Table 1.

The relationship between annual pregnancy-related admissions, total maternal deaths, cases referred to the hospital, deaths among those referred, live births, and percentage survival are cross-tabulated in Table 2. A total of 18,728 pregnancy-related admissions were recorded, of which 18,510 (98.8\%) survived. About 633 (3.4\%) were referred either from hospitals of lower status or came unbooked, and $26.7 \%$ of those classified as referrals died. About $73.2 \%$ of those who died resulted from the referred cases.

Table 3 shows the sociodemographic characteristics of those who died in hospital during the review period. Most of the women $(65.3 \%)$ who died were in the highly active reproductive age group (20-34 years), and 16.8\% were

Table I Annual trends in maternal mortality

\begin{tabular}{llll}
\hline Year & $\begin{array}{l}\text { Total deliveries } \\
\text { (live births) }\end{array}$ & $\begin{array}{l}\text { Maternal } \\
\text { deaths }\end{array}$ & $\begin{array}{l}\text { MMR/I00,000 } \\
\text { live births }\end{array}$ \\
\hline 1999 & 826 & 25 & 3026.6 \\
2000 & 874 & 30 & 3432.5 \\
2001 & 905 & 23 & 2541.4 \\
2002 & 901 & 22 & 2441.7 \\
2003 & 935 & 20 & 2139.0 \\
2004 & 1,197 & 17 & 1420.2 \\
2005 & 1,229 & 9 & 732.3 \\
2006 & 1,849 & 25 & 1352.1 \\
2007 & 1,949 & 20 & 1026.2 \\
2008 & 2,165 & 18 & 831.4 \\
2009 & 2339 & 22 & 940.6 \\
TOTAL & 15,264 & 231 & 1513.4 \\
\hline
\end{tabular}

Abbreviation: MMR, maternal mortality ratio (1513.4/100,000 live births). 
Table 2 Cross-tabulation of total admissions, deaths, referred cases, referred deaths, live births, and percentage of survivors

\begin{tabular}{|c|c|c|c|c|c|c|}
\hline Year & $\begin{array}{l}\text { Total admissions } \\
\text { in labor }(n)\end{array}$ & $\begin{array}{l}\text { Total } \\
\text { deaths (n, \%) }\end{array}$ & $\begin{array}{l}\text { Total } \\
\text { referred (n, \%) }\end{array}$ & $\begin{array}{l}\text { Total deaths } \\
\text { from referrals }(n, \%)\end{array}$ & $\begin{array}{l}\text { Total live } \\
\text { births (n) }\end{array}$ & Survivors (\%) \\
\hline 1999 & 881 & 25 & 52 & 20 & 826 & 97.7 \\
\hline 2000 & 968 & 30 & 61 & 22 & 874 & 97.7 \\
\hline 2001 & 966 & 23 & 48 & 17 & 905 & 97.6 \\
\hline 2002 & 948 & 22 & 50 & 16 & 901 & 97.7 \\
\hline 2003 & 1146 & 20 & 58 & 13 & 935 & 98.3 \\
\hline 2004 & 1614 & 17 & 72 & 11 & 1197 & 98.9 \\
\hline 2005 & 1538 & 9 & 66 & 5 & 1229 & 99.4 \\
\hline 2006 & 1874 & 25 & 60 & 22 & 1849 & 98.7 \\
\hline 2007 & 2529 & 20 & 49 & 15 & 1949 & 99.2 \\
\hline 2008 & 2963 & 18 & 55 & 11 & 2165 & 99.4 \\
\hline 2009 & 3301 & 22 & 62 & 17 & 2339 & 99.3 \\
\hline Total & 18,728 & 231 (I.2) & $633(3.4)$ & 169 (26.7) & 15,264 & $98.8^{*}$ \\
\hline
\end{tabular}

*Total maternal survivors $=18,510$.

younger than 20 years. The age of about $7.4 \%$ of the women could not be ascertained. About $33.3 \%$ of those who died had completed at least primary education, while $25.1 \%$ had either partly or fully completed their secondary education. Eight women $(3.5 \%)$ had tertiary education, while the educational attainment of about $23.4 \%$ was not stated. In total, $67.1 \%$ of the women were married, $26.8 \%$ were single, and about $6.1 \%$ were cohabiting. There were no recorded cases of separation

Table 3 Sociodemographic characteristics of the maternal deaths

\begin{tabular}{lll}
\hline & Number & Percentage \\
\hline Age (years) & 7 & \\
$<15$ & 32 & 3.0 \\
$15-19$ & 49 & 13.8 \\
$20-24$ & 102 & 21.2 \\
$25-34$ & 24 & 44.2 \\
$35-44$ & 17 & 10.4 \\
Not stated & 231 & 7.4 \\
Total & & 100.0 \\
Educational level & 34 & \\
Partial primary & 77 & 14.7 \\
Complete primary & 28 & 33.3 \\
Part secondary & 30 & 12.1 \\
Complete secondary & 8 & 13.0 \\
Tertiary & 54 & 3.5 \\
Not stated & 231 & 23.4 \\
Total & & 100.0 \\
Marital status & 155 & \\
Married & 62 & 67.1 \\
Single & 14 & 26.8 \\
Cohabiting & 231 & 6.1 \\
Total & & 100.0 \\
Employment status & 49 & 100.0 \\
Employed & 128 & 21.2 \\
Unemployed & 26 & 55.4 \\
Student & 28 & 11.3 \\
Unknown & & 12.1 \\
Total & & 1 \\
\hline & & \\
& &
\end{tabular}

or divorce. Those who were unemployed constituted 55.4\%. However, $21.2 \%$ were employed, $11.3 \%$ were students, while in $12.1 \%$ of cases occupation was not stated.

Table 4 shows the medical and social causes of the maternal deaths in hospital. Obstetric hemorrhage was the largest single cause of death, accounting for $33.4 \%$ of mortality. However, primary postpartum hemorrhage accounted for $28.6 \%$ of deaths. This was followed closely by hypertensive diseases

Table 4 Medical and social causes of maternal deaths

\begin{tabular}{lll}
\hline & Number of deaths & Percentage \\
\hline Medical cause & & \\
Antepartum hemorrhage & $1 \mathrm{I}$ & 4.8 \\
Postpartum hemorrhage & 66 & 28.6 \\
Prolonged obstructed & $2 \mathrm{I}$ & 9.1 \\
Labor/ruptured uterus & & \\
Sepsis & 33 & 14.3 \\
Severe pre-eclampsia/ & 49 & 21.2 \\
eclampsia & & \\
HIV/AIDS in pregnancy & $1 \mathrm{I}$ & 4.7 \\
Hepatitis/jaundice in & 3 & 1.3 \\
pregnancy & & \\
Malaria/anemia in pregnancy & 12 & 5.2 \\
Ectopic pregnancy & 6 & 2.6 \\
Abortion & 15 & 6.5 \\
Anesthesia & 4 & 1.7 \\
Total & $23 \mathrm{I}$ & 100.0 \\
Delays (n) & 20 & 8.6 \\
Type I & 82 & 35.5 \\
Type II & 17 & 7.4 \\
Type III & 112 & 48.5 \\
Total & $23 \mathrm{I}$ & $100.0 \%$ \\
Causes of delay & & \\
Delayed referral & 36 & 32.1 \\
Lack/or inadequate blood & 34 & 30.4 \\
Refused blood transfusion & 8 & 7.1 \\
Inability to pay fees & 15 & 13.4 \\
Personnel problems & 15 & 13.4 \\
Lack of drugs/light/logistics & 4 & 100.0 \\
Total & 112 & \\
\hline & & \\
\hline
\end{tabular}


Table 5 Pattern of health-seeking behavior and duration of admission before death

\begin{tabular}{lll}
\hline & Number of deaths & Percentage \\
\hline Place of initial care & & \\
None & 160 & 69.3 \\
Hospital of lower status & 44 & 19.0 \\
Same hospital & 27 & 11.7 \\
Total & 23 I & 100.0 \\
Duration of admission before death (hours) & \\
$\leq 24$ & 77 & 33.3 \\
$25-48$ & 64 & 27.7 \\
$49-96$ & 83 & 35.9 \\
97 hours-10 days & 5 & 2.2 \\
$>10$ days & 2 & 0.9 \\
Total & 231 & 100.0 \\
\hline
\end{tabular}

of pregnancy (21.2\%). Sepsis accounted for $14.3 \%$, while obstructed labor/ruptured uterus was responsible for $9.1 \%$ of deaths. Anesthetic death from failed intubations and total spinal was responsible for $1.7 \%$ of the cases. The contribution of other medical causes to the deaths is shown in Table 4.

We also reviewed the delay phenomena in these maternal deaths. The analysis showed that in $8.6 \%$ of the cases there were no delays, $35.5 \%$ died as a result of Type I delay, while $7.4 \%$ had Type II delay. Type III delay was responsible for $48.5 \%$ of the maternal deaths. Of the $112(48.5 \%)$ resulting from Type III delay, failure of the junior health care providers to call a senior staff member early enough to manage serious cases was responsible for $32.1 \%$ of the deaths. About $30.4 \%$ of the deaths were attributed to lack of or inadequate blood for transfusion, while $7.1 \%$ refused blood transfusion for religious reasons. Other causes of Type III delays in this study were inability to pay hospital fees $(13.4 \%)$, personnel problems (13.4\%), and lack of drugs and/or logistic issues (3.6\%)

Patterns of health seeking behavior for antenatal care and delivery are shown in Table 5. About $69.3 \%$ of the patients had no documented antenatal care and were brought as unbooked emergencies. However, $19.0 \%$ of the women attended antenatal care in hospitals of lower status, and were referred to the teaching hospital following onset of complications. It was observed that $11.7 \%$ of the women who died were booked in at the teaching hospital. About $61.0 \%$ of the deaths occurred within 48 hours of admission, while $35.9 \%$ died thereafter, but within four days.

\section{Discussion}

Maternal mortality remains a major public health issue, especially in the developing countries. ${ }^{1,6}$ The maternal mortality ratio at the University of Calabar Teaching Hospital of 1513.4 per 100,000 live births during the study period is worrisome.
However, this is in agreement with similar studies from other parts of the country. ${ }^{1,6,19}$ Teaching hospitals in developing countries deal with high-risk obstetric cases, and so more maternal deaths will be recorded. ${ }^{4}$ The teaching hospital in Calabar is a referral center that receives all cases, including moribund ones, from within and outside the state. With the exception of this teaching hospital, accurate data collection on maternal deaths is lacking throughout the state in particular and in the country as a whole. Where available, the data are not comprehensive. It is therefore expected that the outlying mortality data will underestimate true maternal mortality. Maternal death should therefore be made officially a notifiable event, and data collection enforced in order to review the problem. ${ }^{16} \mathrm{~A}$ closer look at the yearly trends shows that the figures remained very high up to 2004. In 2005 the hospital put in place a strict mortality audit procedure so that detailed enquiries were made into every maternal death. The result was that people were held accountable for their actions and this helped to lower the maternal mortality rate. Confidential enquiries provide collective experience about serious and often rare conditions, and have led to innovative research, guideline development, and significant improvement in patient care.${ }^{16}$ Contrary to the situation in developed countries, there is an inadequacy of trained pathologists in Nigeria to carry out autopsies. This is compounded by the attitude towards post mortem examination by relatives, and it is not surprising that relatives refused a post mortem examination in all these deaths.

The maternal mortality figures rose again in 2006 and 2007 when staff in some departments were agitating for payment of withheld salaries. With improvement in staff remuneration, as well as improvement in infrastructures at the hospital, the subsequent years in this study were characterized by improved public confidence, resulting in increased delivery rates and a fall in maternal mortality figures. This implies that socioeconomic determinants have a strong influence on maternal morbidity and mortality. ${ }^{4}$ The reduction of $68.9 \%$ in maternal deaths in 2009 from the 1999 figures was evident. However, when compared with a maternal mortality rate of 12.1 per 100,000 live births in The Netherlands and 13.8 per 100,000 live births in the United Kingdom, the data presented in this study could be described as outrageous. ${ }^{16}$ Given that the cream of Nigeria's highly skilled manpower and facilities are located at this teaching hospital, these figures should be able to be reduced to an absolute minimum.

Looking at Table 2, the overall survival rate of at least $90 \%$ of women admitted with pregnancy-related conditions is gratifying, especially given that those who died accounted for only $1.2 \%$. Most cases referred to the center 
were emergencies that came in in a moribund state, at least $70 \%$ of whom died. The majority $(65.3 \%)$ of those who died were in the very active reproductive age group (20-34 years), and $16.8 \%$ were younger than 20 years. This is in agreement with previous studies. ${ }^{1,6-10,13,18}$

Most of those who died had one form of education or another, including eight women who had tertiary education. Education usually affords the woman the opportunity to make the right decision to save herself, especially during an emergency health situation. ${ }^{9}$ It is generally known that education has a positive impact on reproductive behavior and maternal health standards. ${ }^{9,11}$ However, it can be deduced that factors other than educational level contributed to maternal mortality in this review. Maternal mortality is multifaceted in Nigeria, arising from a chaotic social, political, and economic situation leading to poor obstetric care. ${ }^{11}$ The majority of those who died (67.1\%) were married. About $21.2 \%$ of these women were employed in a formal salaried job. Other variables, such as perception and superstitious beliefs, play major roles in maternal deaths in these parts of the world. ${ }^{11,17}$ The influence of faith-based churches in maternal mortality is enormous in Nigeria, and contributes immensely to antenatal defaulting, as well as a negative perception towards medical care. ${ }^{17,18}$ Many of these churches attempt to manage emergency obstetric cases, and only send them to the hospital when the patient is moribund. Thus, people's spiritual beliefs have a significant impact on their health-seeking behavior. ${ }^{17,18}$

The medical and social causes of the maternal deaths recorded at the University of Calabar Teaching Hospital are not different from those at other centers in Nigeria. ${ }^{1,6}$ Obstetric hemorrhage remains the leading cause of maternal mortality, and accounted for $33.3 \%$ of the deaths in this review. However, this is not the case for hypertensive disorders of pregnancy, which are the leading cause of maternal death in The Netherlands. ${ }^{16}$ Hypertensive disorders of pregnancy were the second leading cause of death, accounting for $21.2 \%$ of the deaths in our study, and were the leading cause of death in earlier studies from Maiduguri, Kano, and Lagos. ${ }^{6}$ It is important to state that some of these deaths may be due to multiple factors, because a ruptured uterus can be complicated by hemorrhage and sepsis, and delay in intervention may worsen the outcome.

Type III delay accounted for almost half of all the deaths. This is less than reports from Benin City ${ }^{19}$ in Nigeria, but higher than in an earlier report from Ile-Ife in Nigeria. ${ }^{18}$ The main reasons for these deaths were delayed referral, inadequate blood for transfusion, or refusal of blood for religious reasons. The concept of a user fee as a basis for treating women who require emergency obstetric care has a direct relationship with medical emergencies, deliveries, and the number of women with complications. ${ }^{20}$ Normal deliveries fall when user fees are introduced or increased. ${ }^{20}$ In addition, the inability of junior health care providers to call senior staff early on to manage serious cases creates a dangerous vacuum in instituting definitive care, and was responsible for $32.1 \%$ of the deaths in our study. Some of these women present late at night with serious obstetric emergencies and may be left in the care of a junior resident doctor who lacks the knowledge and skill to attend such a serious problem. Hospital policies must be revised such that senior residents and consultants on call are contacted as soon as a life-threatening emergency arrives in a health care facility to reduce the delays which frequently occur. This appears to be commoner in developing countries where communication facilities and transportation systems are poor. We believe that reduction of maternal deaths attributable to Type III delay can be achieved with the provision of quality obstetric care services in the developing countries. ${ }^{20,21}$

Looking at the health seeking behavior for antenatal care, delivery, and the duration of admission before death, it is clear that over $69 \%$ had no documented antenatal care or history of visiting a health facility. Over $60 \%$ of these women died within 24 hours of admission. They were all brought in as emergencies. This confirms earlier reports. ${ }^{2,6-9}$

\section{Conclusion}

The maternal mortality ratio in our tertiary hospital during the study period is still very high compared with what is achieved in the developed world. There was a downward trend in the maternal death ratio, but it was far from acceptable. The majority of these deaths were preventable. Efforts must therefore be made on the part of health care providers, hospital managers, individuals, and government to maintain the current downward trend in our maternal mortality ratio to meet the expectation of the millennium development goal of reduction in maternal deaths by $75 \%$ in $2015 .^{22}$ This can be done by setting up safe motherhood committees that will adequately audit all maternal deaths, instill discipline, and be responsible for emergency obstetric care. Regular skill-building workshops will also keep health care providers aware of the need to make motherhood safer. ${ }^{12}$ There is also an urgent need to increase public awareness of maternal health issues through the media, community associations, churches, and community leaders. International efforts to assist developing countries in reducing maternal deaths must be sustained. 


\section{Acknowledgment}

The authors are grateful to the medical records department of the University of Calabar Teaching Hospital for providing the data and case files used for this study. We are also grateful to our departmental staff for making very useful suggestions on how to reduce maternal deaths in the hospital.

\section{Disclosure}

The authors report no conflict of interest in this work.

\section{References}

1. Maternal and Child Health. Nigeria Demographic and Health Survey 2003. Calverton, MD: National Population Commission of Nigeria; 2004.

2. Bankole A, Sedgh G, Okonofua F, Imarhiagbe C, Hussain R, Wulf D. Barriers to safe motherhood in Nigeria. New York, NY: Guttmacher Institute; 2009 .

3. Chatterjee A, Mukhopadhyay G. Safe motherhood. In: Arulkumaran S, Sivanesaratnam V, Chatterjee A, Kumar P, editors. Essentials of Obstetrics. New Delhi: Jaypee Brothers, Medical Publishers Pty Ltd; 2004.

4. Steer P. Maternal mortality - the role of the obstetrician. Br J Obstet Gynaecol. 2010;117

5. List of Countries by Life Expectancy, United Nations, 2005-2010. Available at: http://en.wikipedia.org/wiki/List_of_countries_by_life_ expectancy. Accessed Jul 14, 2010.

6. Society of Gynecology and Obstetrics of Nigeria (SOGON). Status of emergency obstetric services in six states of Nigeria. A project report submitted to the Macarthur Foundation, USA, May, 2004.

7. Pittroff R, Johanson R. Safe motherhood - an achievable and worthwhile aim. In: Studd J, editor. Progress in Obstetrics and Gynecology. London: Churchill Livingstone; 1997.

8. Briggs ND. Maternal mortality in sub-Saharan African: The problems and prevention. Trop J Obstet Gynaecol. 1994;2:8-11.

9. Harrison KA, Bergstrom S. Poverty, deprivation and unsafe motherhood. In: Lawson JB, Harrison KA, Bergstrom S, editors. Maternity Care in Developing Countries. London: RCOG Press; 2001.
10. Maternal mortality. National HIV/AIDS\& Reproductive Health Survey (NARHS) Nigeria. 2005:105-109.

11. Harrison KA. The struggle to reduce high maternal mortality in Nigeria. Afr J Reprod Health. 2009;13:9-20.

12. Maine D. Safe motherhood progress, options and issues. New York, NY: Columbia University Center for Population and Family Health; 1991.

13. Ransom EK, Yinger NV. Making motherhood safer: Overcoming obstacles on the pathway of care. Washington, DC: Population Reference Bureau; 2002;1-36.

14. Okonofua FE, Abejide OR, Makanjuola RO. Maternal mortality in Ile-Ife, Nigeria. A study of risk factors. Stud Fam Plann. 1992;23: 319-324.

15. Report of the 2006 National Population Census, Cross River State. Federal Republic of Nigeria Official Gazette. 2009;2:B25-B26.

16. Walker J. Confidential enquiries into maternal mortality. Br J Obstet Gynaecol. 2010;117:379-381.

17. Umoiyoho AJ, Abasiattai AM, Udoma EJ, Etuk SJ. Community perception of the causes of maternal mortality among the Annang of Nigeria's South-East coast. Trop J Obstet Gynaecol. 2005;22:189-192.

18. Etuk SJ, Itam JI, Asuquo EEJ. Role of spiritual churches in antenatal clinic defaulters in Calabar, Nigeria. East Afr Med J. 1999;76: 639-643.

19. Omo-Aghoja LO, Aisien OA, Akuse JT, Bergstrom S, Okonofua FE. Maternal mortality and emergency obstetric care in Benin City, SouthSouth Nigeria. J Clin Med Res. 2010;2:55-60. Available at: http://www. academicjournals.org/JCMR/PDF/PDF2010/Apr/Omo-Aghoja\%20 et\%20al.pdf. Accessed Jul 14, 2010

20. The Prevention of Maternal Mortality Network. Situation analyses of emergency obstetric care: Examples from eleven operations research projects in West Africa. Center for Population and Family Health, Columbia University. Soc Sci Med. 1995:40:657-667.

21. Adamu YM, Salihu HM, Sathiakumar N, Alexander GR. Maternal mortality in Northern Nigeria: A population-based study. Eur J Obstet Gynecol Reprod Biol. 2003;109:153-159.

22. World Health Organization. Road map for accelerating the attainment of the MDGs related to maternal and newborn health in Africa. World Health Organization. 2005. Available at: http://www.afro.who.int/ whd2005/mdg-roadmap-eng.pdf. Accessed Jul 14, 2005.
International Journal of Women's Health

\section{Publish your work in this journal}

The International Journal of Women's Health is an international, peerreviewed open-access journal publishing original research, reports, reviews and commentaries on all aspects of women's healthcare including gynecology, obstetrics, and breast cancer. Subject areas include: Chronic conditions (migraine headaches, arthritis, osteoporosis);

\section{Dovepress}

Endocrine and autoimmune syndromes; Sexual and reproductive health; Psychological and psychosocial conditions. The manuscript management system is completely online and includes a very quick and fair peer-review system. Visit http://www.dovepress.com/ testimonials.php to read real quotes from published authors. 